\title{
Assessing the Potential of In-Gallery Seismic Shots in Exploring Buried Structures of 'Ain Zubaidah Using Acoustic Wavefield Modeling
}

\author{
Talal A. Mokhtar \\ Department of Geophysics, Faculty of Earth Sciences, \\ King AbdulAziz University \\ P.O. Box 80206, Jeddah 21589, Saudi Arabia \\ tmokhtar@kau.edu.sa
}

Received: 5/11/2006

Accepted: 25/3/2007

\begin{abstract}
A numerical modeling approach, approximating the solution of the 2-D heterogeneous, acoustic wave equation with second-order accuracy in both time and space, is utilized to unravel the hidden potential of the in-gallery seismic shooting technique as an effective tool in accurately locating buried shafts (Karez), as well as gallery routes, of 'Ain Zubaidah, Makkah Al Mukarramah area, Kingdom of Saudi Arabia.
\end{abstract}

Numerical models indicated that gallery routes could vividly be delineated as conspicuous, high amplitude reflections and that should equally be true for deeper galleries because of the high $\mathrm{S} / \mathrm{N}$ ratio of seismic wave energy generated by in-gallery seismic shots. This should provide an accurate and cost-effective tool for exploring relatively wide areas.

Although these findings should be applicable to similar geological problems, even in subsurface structures characterized by velocity inversions, a word of caution, however, is that they are applicable only to air-filled or slightly water-filled galleries. This situation should change when ground water level increases during rainy seasons, where the velocity of loose saturated sediments should at a minimum be around that of water $(1500 \mathrm{~m} / \mathrm{sec})$, masking their presence. This is also true for shafts inundated in ground water. Accordingly, the season when to carry field surveys is important in gaining similar success in other areas. 


\section{Introduction}

'Ain Zubaidah, lying within Wadi Nu'man, east of Arafat, Makkah Al Mukarramah, Kingdom of Saudi Arabia, was anciently a main route for supplying water to pilgrims at Arafat and has gone through many phases of maintenance and rebuilding. It essentially consists of a network of stone-lined galleries that are serviced by stone-lined shafts distributed along the gallery network for the purpose of cleaning and maintenance.

The present study has been carried out in the area located in the western part of Wadi Nu'man which extends between the foothill of Al Hada Mountain and south of Arafat area (Fig.1). Wadi Nu'man discharges its water to the Red Sea in the West and is considered as one of E-W drainage elements which cuts across the Arabian Shield in Western Saudi Arabia.

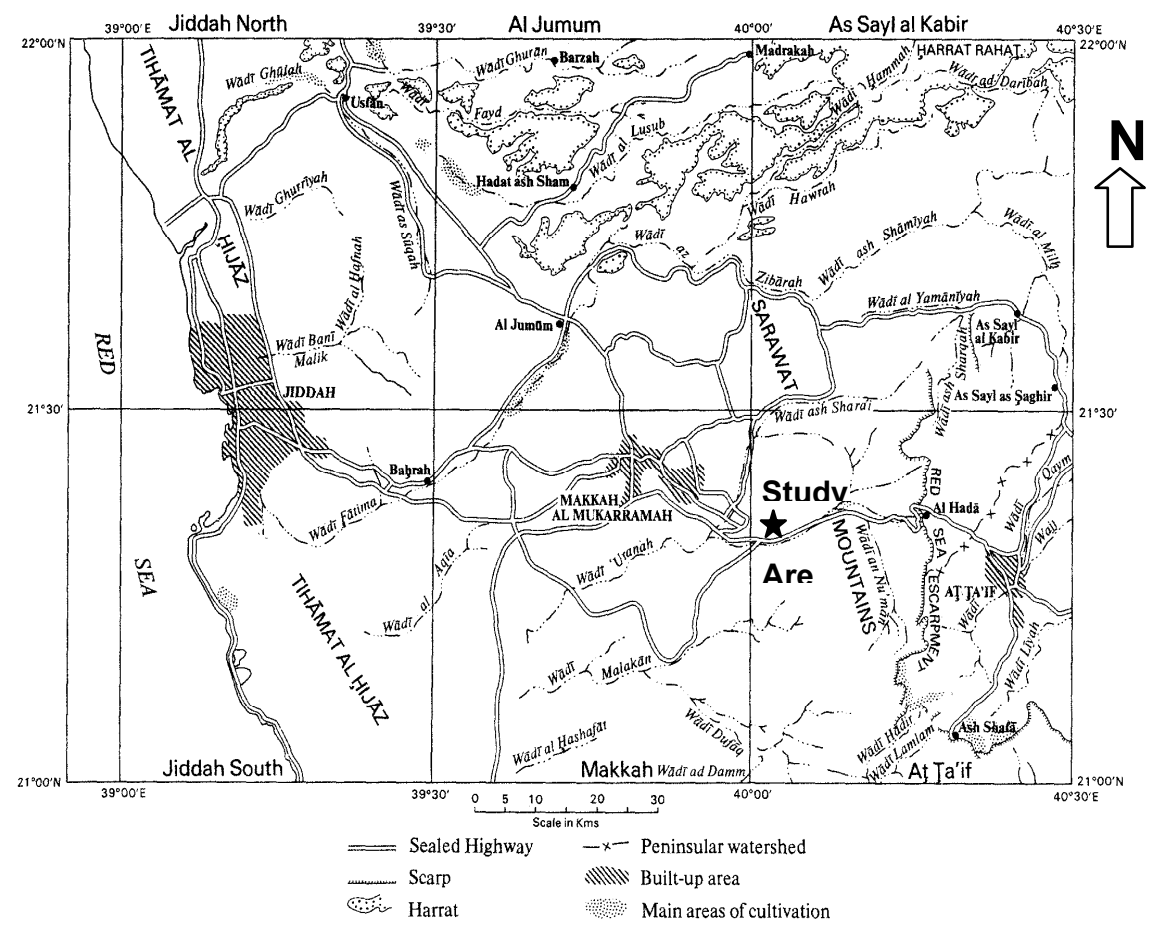

Fig. 1. Location of the study area.

Among the difficulties hindering rehabilitating and maintaining the 'Ain Zubaidah System is that many of the shafts (Karez) servicing the galleries have been blocked and even totally buried at variable depths 
under the wadi sediments over the years of abandonment of the network. In frequent situations, the shafts, which are usually less than $2 \mathrm{~m}$ in diameter, are buried deeper than $10 \mathrm{~m}$ and the gallery depth exceeds $30 \mathrm{~m}$. Critical to the efforts of reviving the System is then finding means to locate the buried shafts so that the efforts of cleaning the gallery segments could be resumed.

To this end, Mokhtar and El-Difrawy (2000) applied the simple procedure schematized in Fig. 2, where a person was descended into the gallery through one of the usable shafts and generated seismic energy inside the gallery near the buried and blocked shaft using a sledgehammer. The energy was then recorded at the surface using a surface geophone array and the closest approach to the in-gallery shot (shaft) could be approximately determined as corresponding to geophone locations with the least first arrival times. The geophone array was then moved in the direction of least first arrival times and the shooting and recording repeated until global first arrival traveltime minima were recorded pointing to the closest approach to the surface projection of the blocked and buried shaft. This interpretation, however, should yield acceptable results only if waves transected an earth volume having essentially the same seismic velocity characteristics along travel paths; that is, path length is the sole variable.

Despite the appeal of this approach due to its simplicity of execution and interpretation, a straightforward interpretation of the recorded first arrivals in terms of buried shaft location and depth might not always be possible. This might be particularly true in case of a deeply buried, soilfilled shaft because of several factors including:

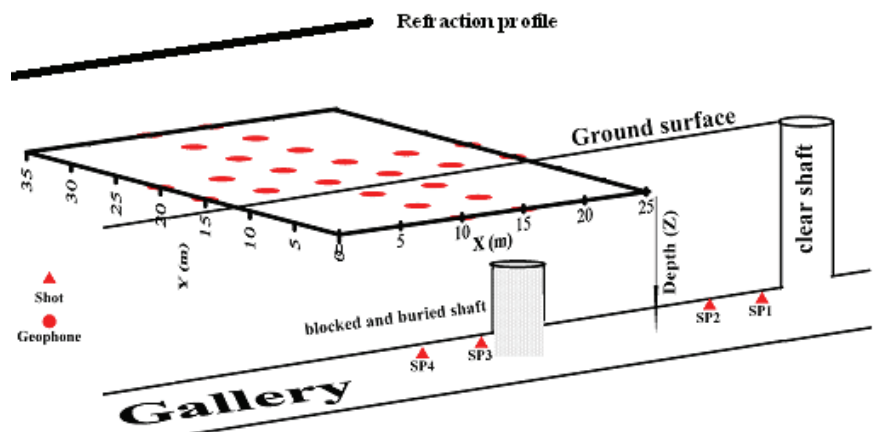

Fig. 2. A scheme illustrating the geophone layout and seismic refraction profile in relation to the clear and blocked shafts, the shot locations, and the gallery (adapted from Mokhtar and El-Difrawy, 2000). 
1- The soil filling the shaft might have a much lower seismic velocity than the surrounding media thus producing time delays. So instead of seeking minimum traveltimes as a shaft location indicator, traveltime maxima should be sought;

2- Soils, especially those above the water table, are intrinsically extremely heterogeneous both geologically and seismically; this is besides the strong vertical velocity gradients dominant in these soils. Thus, the condition that waves transect an earth volume having essentially the same seismic velocity characteristics along the travel path is seldom met; the path length is no longer the sole variable in determining arrival times;

3- Short seismic experiments are intrinsically high resolution (short wavelength) in nature because of the low velocity of surface material and the rich content of high frequencies in travelling waves, a situation which is not enough compensated for by the high attenuation of near surface material. Hence, small-scale velocity heterogeneities are expected to reflect themselves on the wavefield and, consequently, traveltimes arriving at the surface detectors, rendering it virtually impossible to interpret first arrival traveltime anomalies in terms of shaft spatial location in any simple way. This is particularly true, specially that the source used in the layout of Fig. 2 is deep in the ground (ca. $30 \mathrm{~m}$ ), which permits transmitting high frequency, high $\mathrm{S} / \mathrm{N}$ ratio source signal along most of the travel path to the surface.

All these factors combined should complicate or even prevent a simple, straightforward interpretation of first arrival traveltime anomalies to allow accurate spatial positioning of the geological target, the blocked shaft in the present case. This has led Mokhtar and El-Difrawy (op. cit.) to resort to transmission tomographic inversion of seismic first arrival data, using in-gallery seismic sources and surface receiver arrays, to determine the spatial location (depth to the top and horizontal location) of the buried shaft.

\section{The Objectives}

As stated above, the shafts (Karez) of 'Ain Zubaidah, which are usually less than $2 \mathrm{~m}$ in diameter, are frequently buried deeper than $10 \mathrm{~m}$ and the gallery depth exceeds $30 \mathrm{~m}$. Because of the presence of numerous such cases, drilling was selected as a primary procedure for excavating 
the buried shafts. This, however, required accurate determination of the spatial location of the shafts and, preferably, also the depth to their tops, warranting the search for a procedure that can be applied as routine for solving similar problems. Further, the procedure should be both accurate and cost effective.

One such procedure was the one devised and successfully applied by Mokhtar and El-Difrawy (2000); namely, the approach of using ingallery shooting and surface geophone spreads and transmission tomographic inversion to determine the spatial location of buried shafts. However, since the author interested in as accurate solutions as possible, as well as seeking insight into the wave propagation phenomena associated with blocked and buried shafts that might lead to acquisition procedures and analysis schemes, that can be used in similar situations on a routine basis, The author here further investigates the potential capabilities of this field approach using seismic modeling techniques to synthesize the full seismic wavefield from in-gallery shots.

The present investigation, however, is not restricted to seismic first arrival traveltimes. Instead, the entire seismic wavefield is investigated. Nevertheless, only the vertical component of the wavefield is presented, since almost all traditional seismic field work uses only vertical geophones. In the course of the analysis, the intricacies of the processes complicating direct visual interpretation of first arrival times are deciphered and addressed, and the potential of using later arrivals, specifically reflections, to delineate the location and configuration of the gallery itself is investigated.

\section{The Approach}

In the present investigation, The author used the same field layout of Mokhtar and El-Difrawy (2000) to synthesize the seismic wavefield from some of their relocated in-gallery shotpoints (SP1 through SP4) relative to their tomographically located shaft Fig.2. The author further used, as the initial model for wavefield synthesis, their 2-D velocity model Fig.3 obtained from inverting the data collected along an approximately $125 \mathrm{~m}$ long seismic refraction profile, conducted near their surface geophone spread and parallel to its $\mathrm{X}$-axis. The $35 \mathrm{~m}$ long segment of the velocity model nearest the surface geophone spread is shown in Fig. 4, exhibiting 
strong and variable vertical velocity gradients. This segment is used in all subsequent modeling studies.

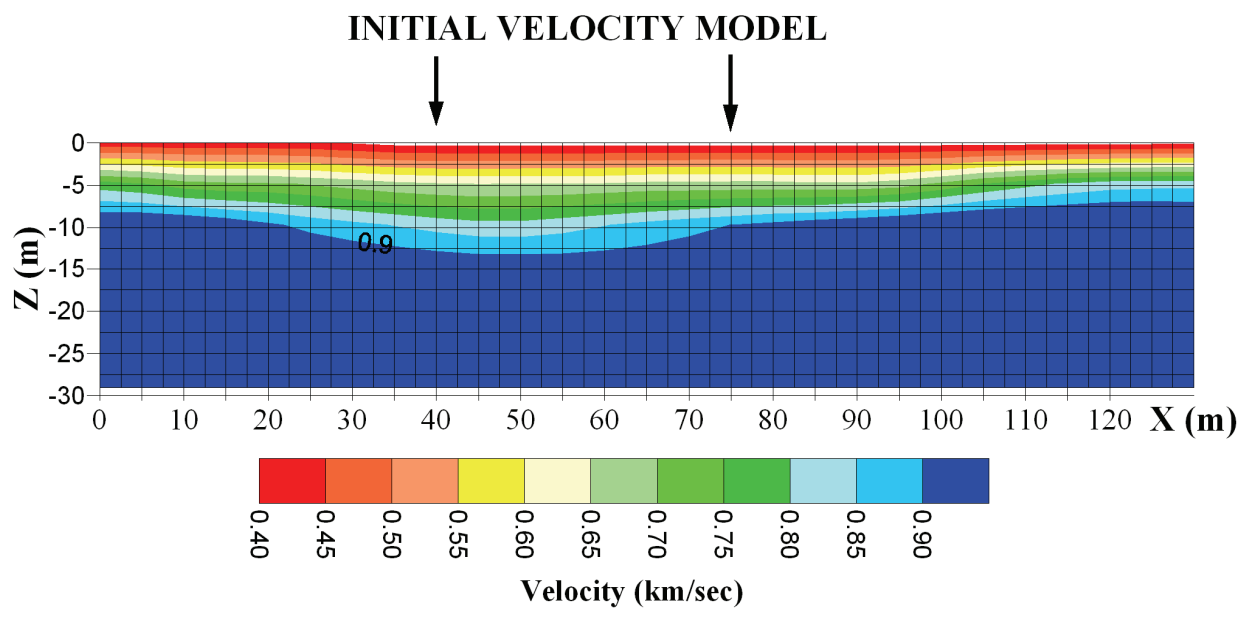

Fig. 3. Regridding of 2-D velocity model for finite-difference (FD) synthesis. Grid size used is $0.5 \times 0.5 \mathrm{~m}$; coarser grid lines are shown here to avoid clutter (velocity model is from Mokhtar and El-Difrawy, 2000).

Various techniques for modeling wave propagation have been developed and are now in common use. Among these are the finitedifference (FD) techniques (Alterman and Karal, 1968; Boore, 1972; and Kelly et al., 1976; and 1982), the finite-elements technique (Smith, 1975; and Chen, 1984); Fourier techniques (Gazdag, 1981; Kosloff and Baysal, 1982; and Fornberg, 1987); and hybrid methods (Gazdag, 1981). The finite-difference techniques are suitable for complex subsurface velocity distributions, because they implicitly handle boundary conditions at velocity contacts and are therefore used in the present investigation.

In this study, the author uses the finite-difference scheme of Keiswetter et al. (1996); Equation (12), to numerically approximate the solution of the 2-D heterogeneous acoustic wave equation (Brekhovskikh, 1960). In their approach, explicit approximations of second-order accuracy for both the spatial and temporal sampling intervals and energyabsorbing boundary conditions are used. A source function is introduced into the solution of the wave equation using a Kronecker delta function, having a value of 1 at the source position and 0 elsewhere, and a discrete time-dependent source function of the form $\mathrm{S}(\mathrm{n} \Delta \mathrm{t})$, where $\mathrm{n}$ is the timestep and $\Delta \mathrm{t}$ is the temporal sampling interval used in modeling. 
As for the time function, The author used the first derivative of a Gaussian function as used by Alford et al. (1974). The velocity model of Fig. 4 was parameterized on a uniform square grid; i.e., velocities were specified at equal node spacing in the $\mathrm{X}$ and $\mathrm{Z}$ directions and forward calculations were performed in Cartesian coordinates assuming a point seismic source. The forward modeling and all aspects of the modelling algorithm are described in detail in Keiswetter et al. (1996).

To satisfy criteria for numerical stability in heterogeneous media and to reduce the grid dispersion phenomenon as described by Alford et al., (1974); and Kelly et al., (1982), a $0.5 \times 0.5 \mathrm{~m}$ square grid and a temporal sampling interval $\Delta \mathrm{t}=0.00034 \mathrm{sec}$ were used. The selected temporal sampling provided for unaliased frequencies as high as $1428 \mathrm{~Hz}$ which was more than adequate even for our short-path, high frequency seismic measurements.

Further, the parameterized velocity model was padded laterally and at the bottom by 33 additional grid cells, to minimize spurious reflections from these artificial, non-acoustic-impedance boundaries. It should be noted, however, that at the bottom of the 30m-depth model of Fig. 3, 4

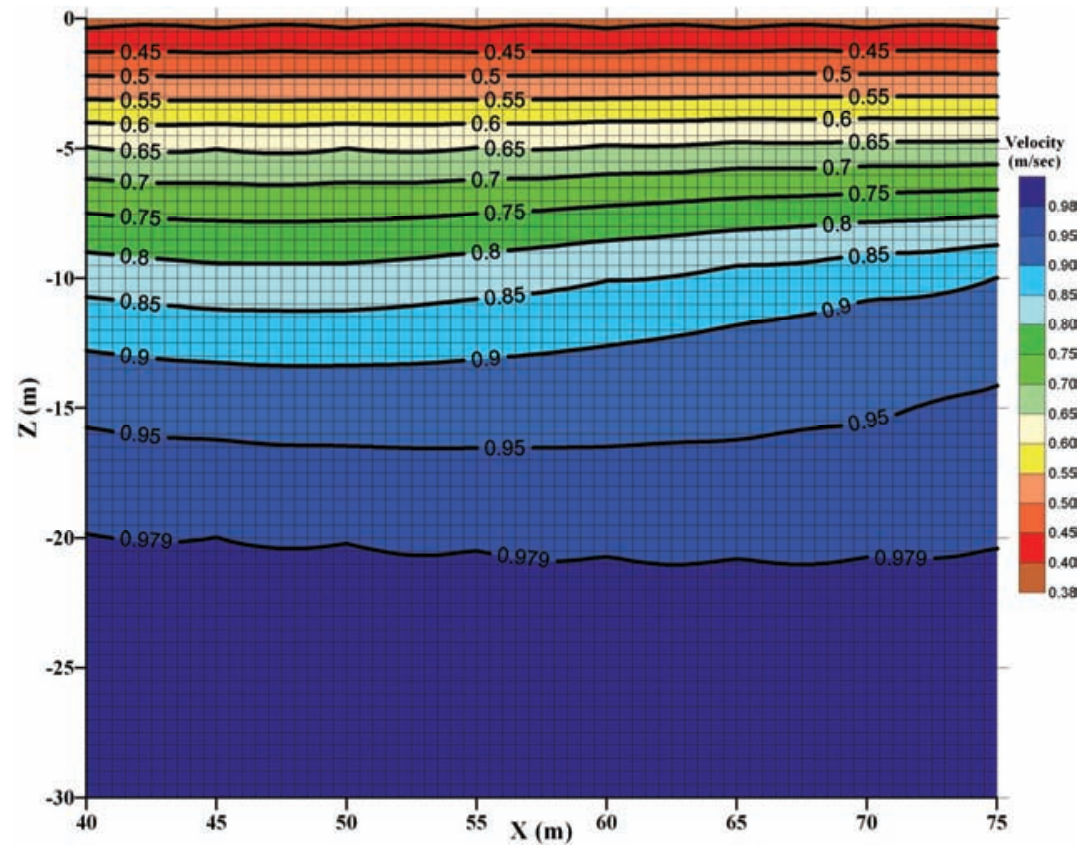

Fig. 4. Initial 2-D velocity model along the segment nearest the surface geophone spread (see Fig. 3). Notice the strong velocity gradients near ground surface. 
grid cells $(1.5 \mathrm{~m})$ having the velocity of air $(340 \mathrm{~m} / \mathrm{sec})$ were added to represent the air-filled gallery. Additional 4 grid cells $(2 \mathrm{~m})$, assigned a velocity of $980 \mathrm{~m} / \mathrm{sec}$, were added at the bottom of the gallery-cells to allow for reflections and refractions from the bottom of the gallery to be incorporated into wavefiled modeling. Beyond these cells, both laterally and downwards, an absorbing boundary condition based on the gradual reduction of wave amplitudes in the vicinity of the boundaries (Cerjan et al., 1985; and Sochacki et al., 1987) was enforced. This reduction was effected by gradual tapering using an exponential function with an exponent of -0.025 reaching its maximum (zero amplitude) at model edges.

\section{Results and Discussions}

The wave phenomena associated with the present geologic situation may be investigated in Fig. 5, which presents snapshots of the seismic wavefield in the $X-Z$ plane generated from SP4 (located at $X=2.5$, $Y=12.5)$. The snapshots were synthesized for the sake of investigating the interaction of the model velocity layers with travelling wave energy in the hypothetical absence of the buried shaft.

In Fig. 5, apart from the complex, non-linear wave phenomena close to the source area (the near-field), the up going direct waves are clearly seen in the $5 \mathrm{msec}$ snapshot and later where they arrive at the ground surface in the $30 \mathrm{msec}$ to $40 \mathrm{msec}$ snapshots. These waves are the one picked as first arrivals on vertical component geophones. In the $10 \mathrm{msec}$ snapshot, reflection from the strong acoustic impedance contrast $(340 / 980 \mathrm{msec})$ at the floor of the gallery is developed and continues travelling upwards in snapshots $20 \mathrm{msec}$ through $50 \mathrm{msec}$. Also noticeable, is the strong down going reflection initiated at a velocity boundary in the $30 \mathrm{msec}$ snapshot. The successful performance of the absorbing boundaries in reducing reflections from model edges is also demonstrated on all snapshots.

Overall then, the snapshots in Fig. 5 demonstrate a simple far-field wave phenomena essentially dictated by the lack of abrupt velocity changes- significant acoustic impedance boundaries- within this velocity section. That is the reason why only small amplitude transmitted and downward reflected energy are stray throughout the snapshots starting at the $30 \mathrm{msec}$ snapshot and later. 
Ground surface at 31.5 depth units

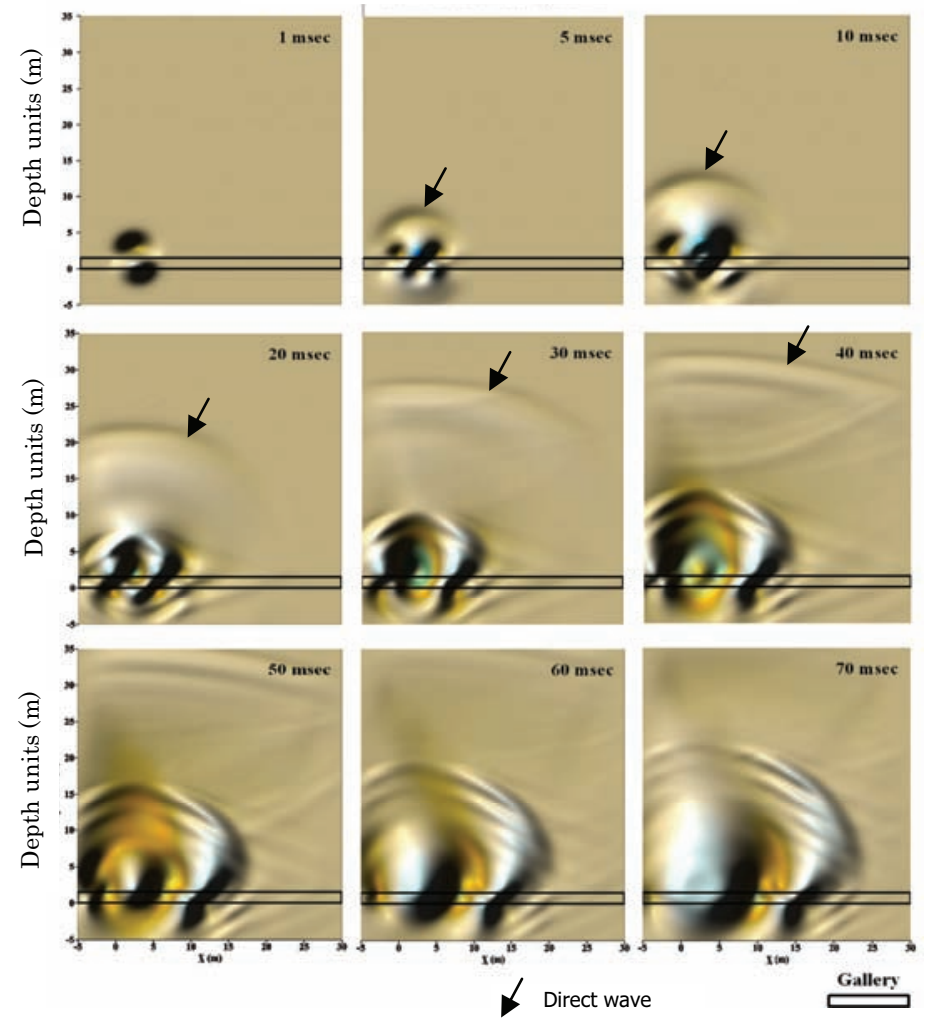

Fig. 5. X-Z snapshots of FD-synthesized full wavefield of SP4 (Shaft hypothetically not crossed). Notice direct waves arriving at the ground surface (depth unit $31.5 \mathrm{~m}$ ) between the $30 \mathrm{msec}$ and $40 \mathrm{msec}$ snapshots.

These phenomena are further illustrated on the corresponding synthetic time section of Fig. 6, where the strong direct waves are conspicuous as first arrivals.

An important finding also illustrated on the synthetic seismic section of Fig. 6 is that the gallery itself is highlighted as a strong event straddled by the direct waves and waves reflected from the bottom of the gallery, where a strong acoustic impedance contrast exists between the air-filled gallery and the underlying material having a seismic velocity of $980 \mathrm{~m} / \mathrm{sec}$. The height of the gallery is also correctly represented by the approximately $9 \mathrm{msec}$ two-way-time separation between the two events, corresponding to the $1.5 \mathrm{~m}$-high gallery. The simple 2 -D velocity model, 
therefore, proves to be adequate for arriving at a subsurface picture accurate enough for gallery route exploration purposes.

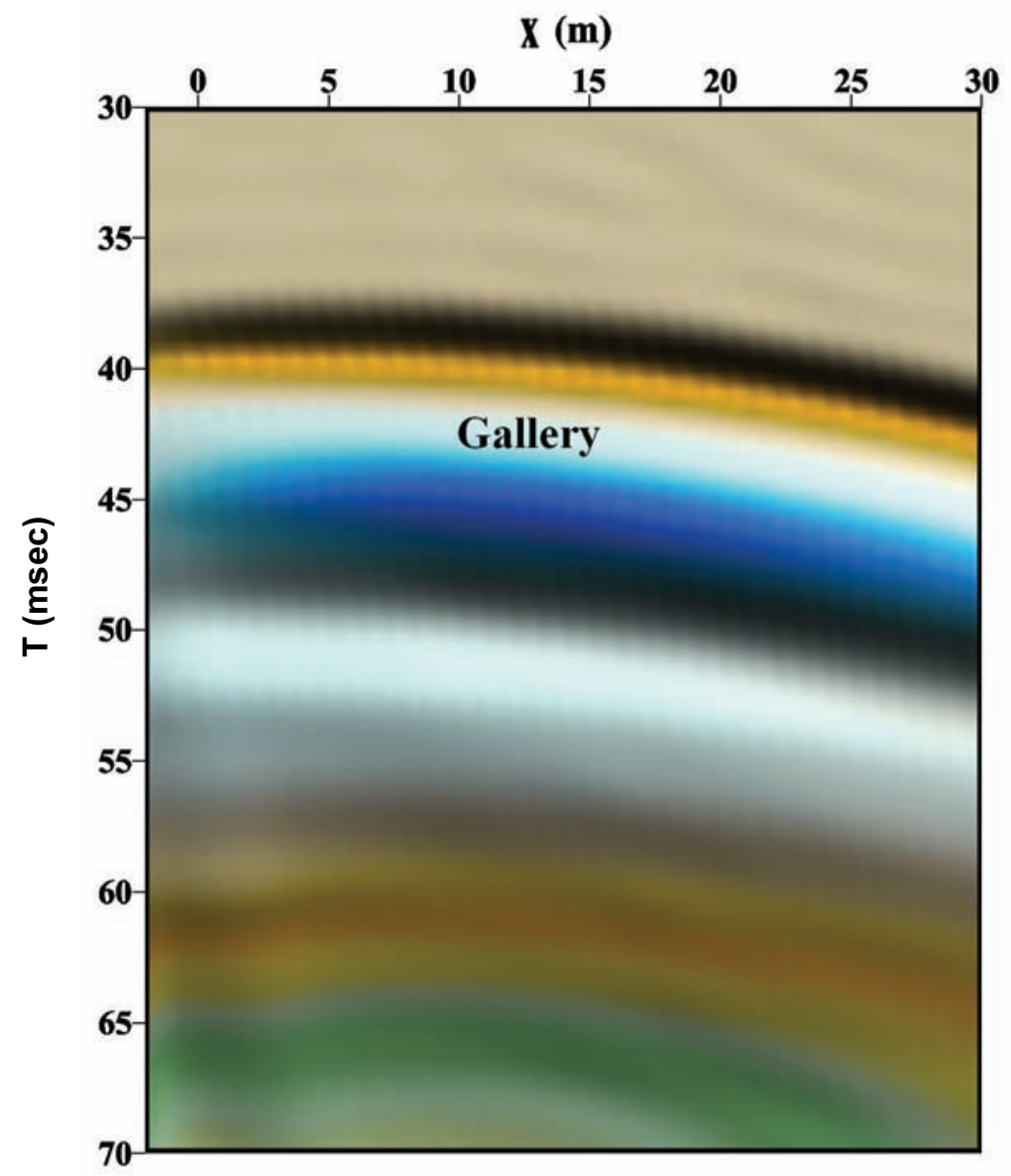

Fig. 6. FD synthetic time section at the ground surface corresponding to the FD-synthesis of SP4 in Figure (5); shaft hypothetically not crossed.

The X-Z snapshots of the synthesized wavefield of the same shotpoint SP4 are illustrated in Fig. 7. Seismic waves now cross the buried shaft tomographically located by Mokhtar and El-Difrawy (2000) at $\mathrm{Y}=12.5 \mathrm{~m}$ with its top lying at an approximate depth of $10 \mathrm{~m}(21.5$ depth units in Figure 7) and filled with a low velocity (ca. $380 \mathrm{~m} / \mathrm{sec}$ ) material. In contrast to the rather simple wavefield presented in Figure (6), the role of the sediment-filled buried shaft in generating reflections and diffractions is evident in the snapshots. 
Again, the up going direct waves are well developed in the $5 \mathrm{msec}$ snapshot. However, in the $10 \mathrm{msec}$ snapshot, the direct waves impinge upon the left high acoustic impedance boundary of the low-velocity shaft giving rise to strong reflected seismic energy propagating across the $\mathrm{X}-\mathrm{Z}$ plane at very large emergence angles towards smaller $X$. These waves are well developed in the $20 \mathrm{msec}$ and later snapshots and are expected to arrive at the surface geophone spread as very late arrivals or as later arrivals outside the present geophone spread. The value of these waves in seismic exploration for the buried shaft is negligible, as I am essentially interested in first arrivals or clear late arrivals. The effort and techniques that are expected to be invested in extracting such later arrivals from

Ground surface at 31.5 depth units
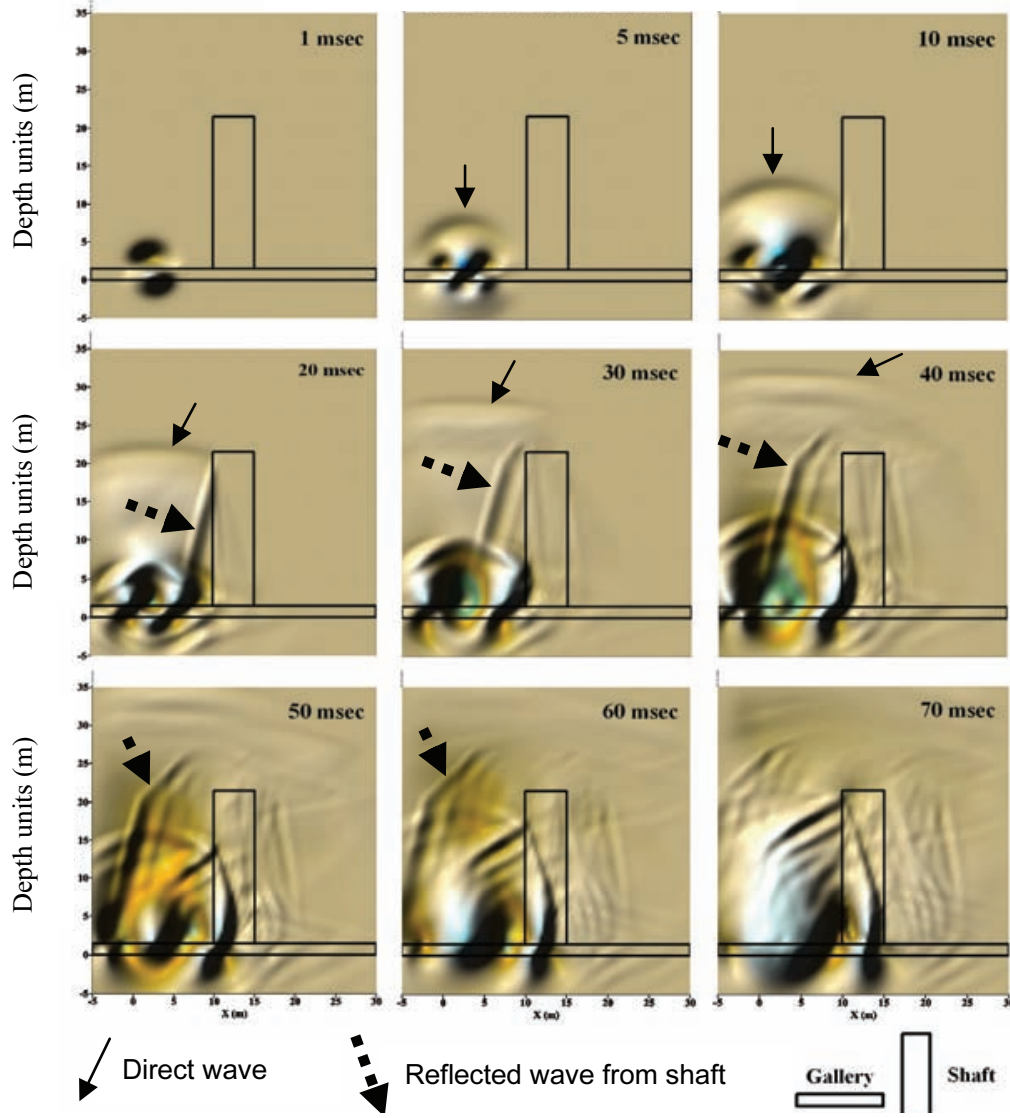

Reflected wave from shaft
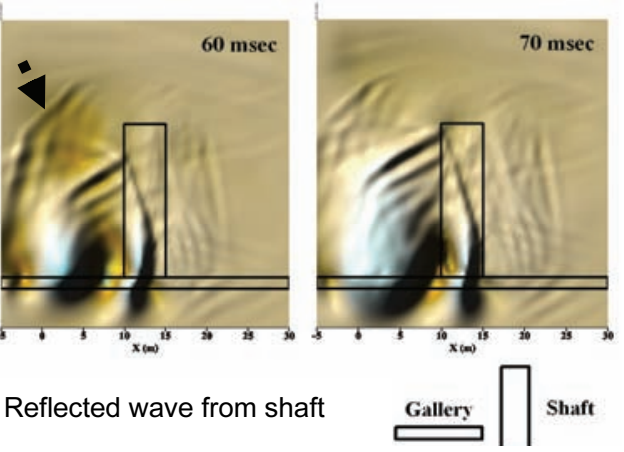

Fig. 7. X-Z snapshots of FD-synthesized full wavefield of SP4 crossing the shaft. Notice the role of the buried shaft in generating reflections and diffractions complicating the otherwise simple upgoing wavefield (shaft location at $Y=12.5 \mathrm{~m}, \mathrm{Z}=10 \mathrm{~m}(21.5$ depth units) is from Mokhtar and El-Difrawy, 2000) 
other entangled later arrivals, as well as the accuracy of the outcome, deem them as unsuitable for the current exploration target.

Still more complicated is the wavefield in the $40 \mathrm{msec}$ and later snapshots, where the seismic energy transmitted through the left boundary of the shaft is reflected at and transmitted through the right high acoustic impedance boundary of the shaft. These, in turn, reverberates inside the shaft giving rise to a very complicated up going and down going seismic energy interfering with diffractions and multiply reflected at the high acoustic impedance gallery base. The shaft now acts as a new line source of seismic energy. Further, the amplitude of the resulting seismic energy at the shaft sides are variable, since the shaft cuts across a horizontal velocity stratification; the acoustic impedance along the sides of the shaft should, therefore, decrease approaching the ground surface.

However, the most profound effects the low-velocity-material-filled shaft has on direct up going seismic waves and the early reflection echoes from the gallery base are that it delays both waves and causes their amplitude to decay as they travel across the shaft. The direct upgoing waves now arrive at the rightmost surface geophones in the 40 msec snapshot with feeble amplitudes.

What is expected to be picked up by the surface vertical geophones is shown by the corresponding synthetic seismic section of Fig. 8B. The direct wave first arrivals are still clearly identifiable. The buried shaft impression is now readily identifiable on the synthetic seismic section in the form of a fault-like criterion caused by the traveltime delays its low velocity induces on direct and reflected waves. The gallery is still evidently highlighted as a strong event straddled by the direct waves and waves reflected from the bottom of the gallery; this time, however, it apparently seems vertically segmented due to the delaying effect of the shaft.

Further, in contrast to the uniform, strong seismic amplitudes of the events in Fig. 8A where the shaft was hypothetically not present, the events in Fig. 8B exhibit variable amplitudes across the $\mathrm{X}$-axis with a strong amplitude decay in the rightmost part of the synthetic section due to the variable acoustic impedance contrast vertically along the shaft boundaries and the strong energy partitioning along those boundaries. The latter synthetic section is also infested with shaft-generated diffractions that are not present in Fig. 8A. Moreover, Fig. 8B exhibits at 
its leftmost part an event with a very low apparent velocity (very steep slope) corresponding to the very high emergence-angle wave energy previously discussed.

It is here worth noting that traveltime offsets (delays) caused by the low-velocity material of the shaft erroneously indicate its true horizontal (surface projection) location. This is further illustrated in Fig. 9 showing the synthetic seismic section of shotpoint SP3 closer to the shaft compared to the synthetics of SP4. Notice that traveltime offsets caused by the shaft migrate further away, and in opposite direction, from its true horizontal location as shots move farther from the shaft. This situation is further elaborated upon in Fig. 10 showing the synthetics for the four ingallery shots SP1 through SP4. These sections also clearly demonstrate the degradation of gallery impression as shots are moved farther from the shaft. Both phenomena are well known in seismic work and are corrected for using various well established seismic migration techniques (e.g. Yilmaz, 1987), which are not common to apply in shallow seismic field investigations (e.g. Black et al., 1994). This, therefore, does not compromise the potential of the field technique of in-gallery seismic shooting and the use of gallery-base reflections in exploring for the shafts and galleries of 'Ain Zubaidah.

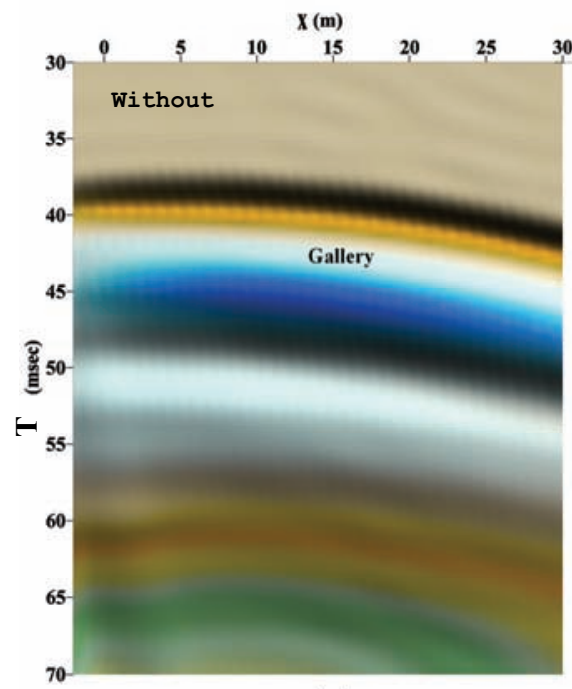

(a)

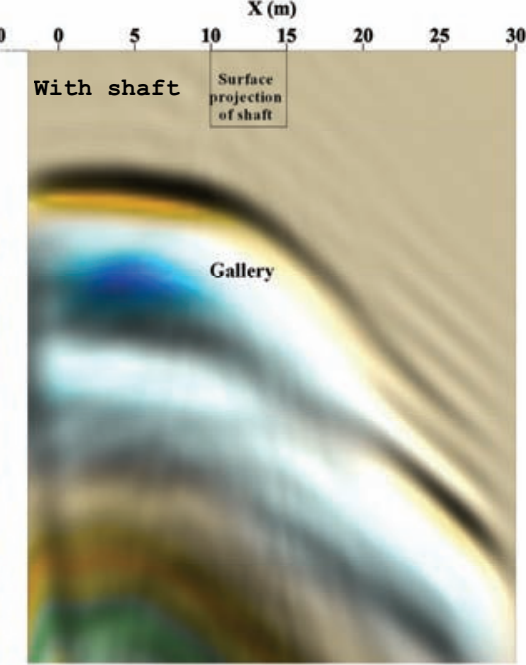

(b)

Fig. 8. FD synthetic time sections at the ground surface (SP4). Notice how reflections (source echoes) from the gallery base serve to delineate the gallery itself in the hypothetical absence (a) or presence (b) of the shaft. Also notice that traveltime offsets caused by the shaft erroneously indicate its true horizontal location. 


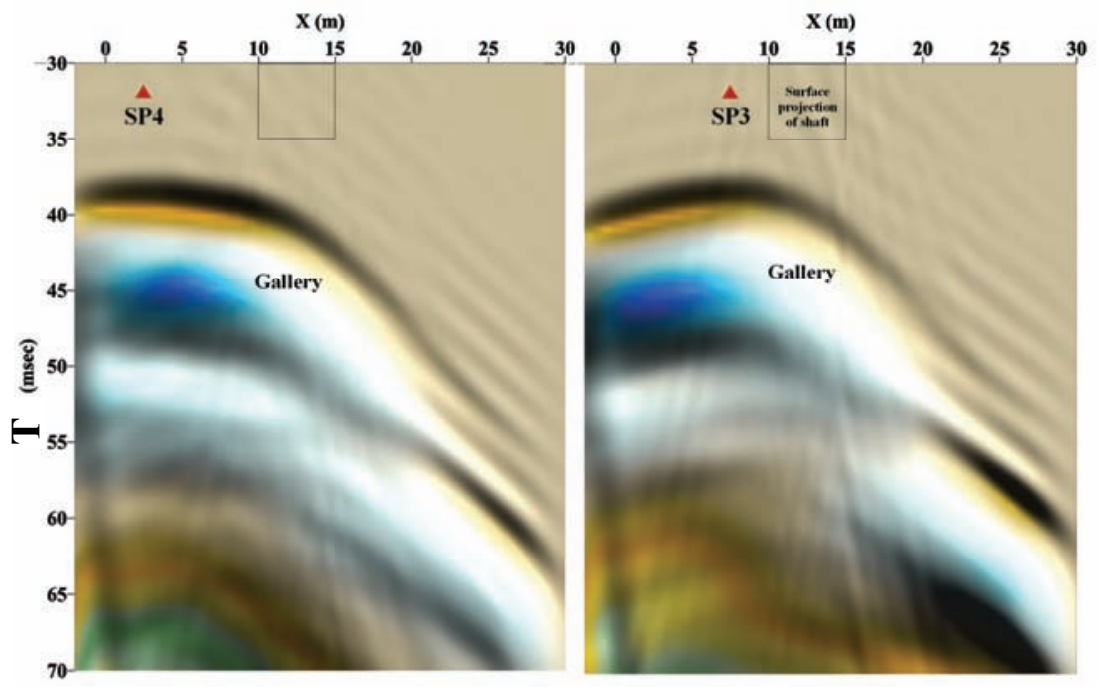

Fig. 9 FD synthetic time sections at the ground surface. Notice that traveltime offsets caused by the shaft migrate further away (and in opposite direction) from its true horizontal location as shots move farther from the shaft.

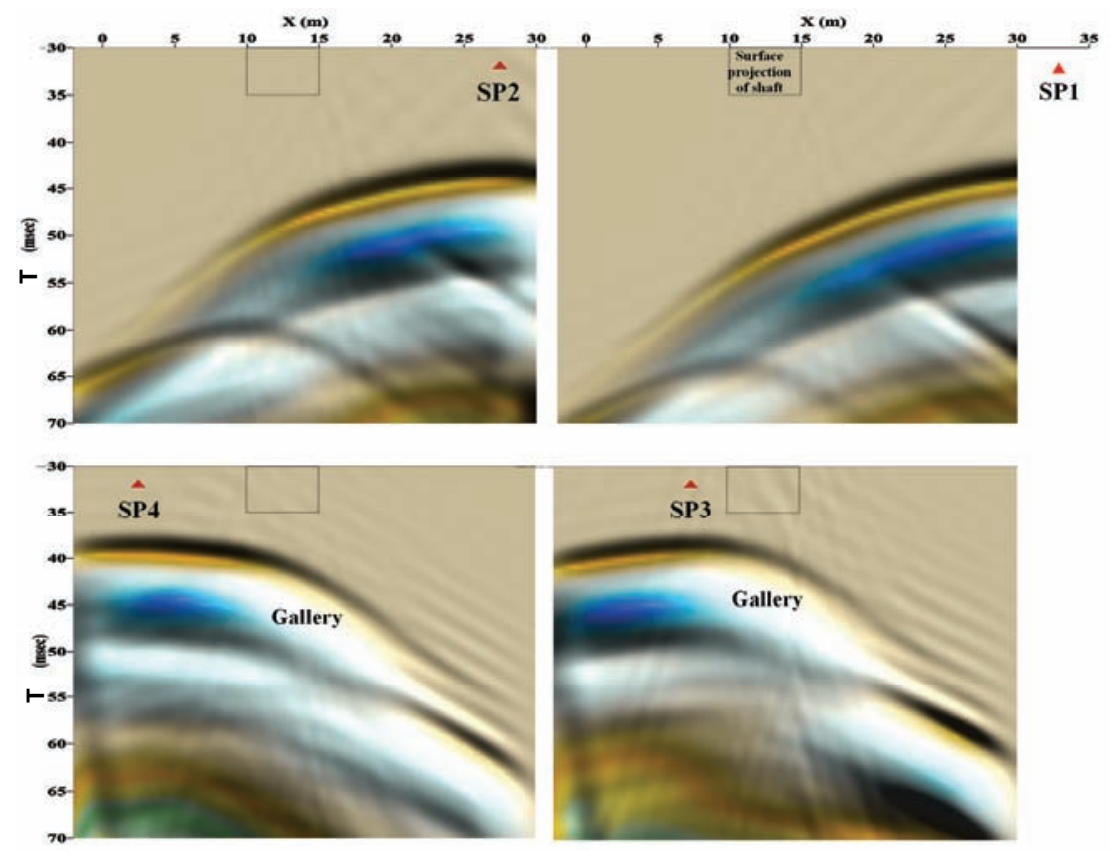

Fig. 10. FD synthetic time sections at the ground surface. Notice that shaft location as reflected on the seismic section is always offset from its true location. Also notice the degradation of gallery impression as shots are farther from the shaft. 
As a concluding remark, based on the afore-presented discussions, it is here emphasized that a simple visual interpretation of raw (unmigrated) first arrival traveltime isochronal surfaces in terms of the location of the surface projection of the buried shaft will always be misleading and not indicative of the true location of the shaft, which will always be shifted opposite to the shot-to-shaft direction. This is further illustrated in Fig. 11 which compares the observed traveltime isochrones for in-gallery shots SP1 through SP4 as obtained by Mokhtar and El-Difrawy (2000) versus corresponding synthetic traveltimes and demonstrates the agreement of the behaviour of the two data sets along constant $\mathrm{Y}=12.5 \mathrm{~m}$ profiles, emphasizing the risk of relying on raw first arrival traveltime isochrones in accurately locating buried shafts, specially when it is the basis for subsequent drilling decisions.

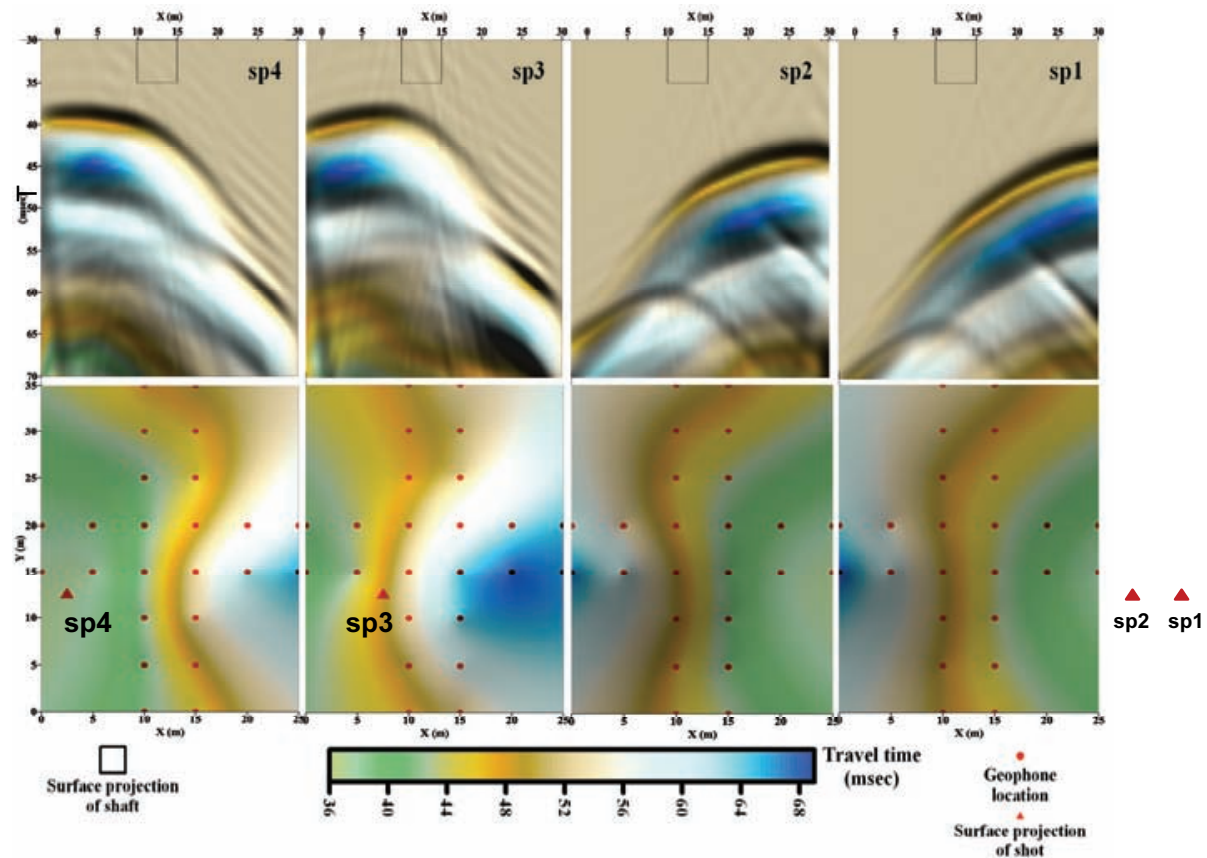

Fig. 11. Observed versus synthetic traveltimes for in-gallery shots SP1 through SP4. Notice the agreement of the behavior of the two data sets along the constant $Y=12.5 \mathrm{~m}$ profile crossing the shaft. Notice that isochronal anomalies always erroneously indicate the shaft location (observed traveltimes are from Mokhtar and ElDifrawy, 2000) . 


\section{Conclusion}

The author has presented through the technique of seismic wavefield modeling the potential of using the innovative seismic field procedure of in-gallery shooting in delineating galleries and shafts of 'Ain Zubaidah, Makkah Al Mukarramah area, Kingdom of Saudi Arabia. In the course of the present investigation, the following conclusions were reached:

1- Bottom-to-surface seismic methods are equally applicable to locating buried shafts and delineating gallery routes. However, later arrivals (reflections) are primary targets for gallery investigations.

2- The location of the surface projection of the buried shaft as might be determined from the visual inspection of raw first arrival traveltime isochrones is misleading, not indicative of the true location of the shaft, and is always shifted in opposite direction of the shot-to-shaft direction. This is a well known phenomenon in seismic work that requires seismic migration, which is not common to apply in shallow seismic field investigations. This, therefore, does not compromise the potential of the field technique of in-gallery seismic shooting and the use of gallery-base reflections in exploring for the shafts and galleries of 'Ain Zubaidah.

3- As the distance of the shot to the shaft increases, the shift of the impression of the shaft on first arrival traveltime isochrones also proportionately increases. Nevertheless, due to the good bottomto-surface seismic energy transmission, relatively wide areas can be surveyed for locating shafts and delineating gallery routes with the help of the additional office work of seismic migration.

4- A word of caution, however, is that since the investigated gallery was empty (air-filled- $340 \mathrm{~m} / \mathrm{sec}$ ) during the survey period, as witnessed by the down-gallery person, the reflections from the gallery base become evident on the synthesized sections as later arrivals. This situation should change when ground water level increases during rain seasons, where the velocity of loose saturated sediments should at a minimum be around that of water $(1500 \mathrm{~m} / \mathrm{sec})$, hence, masking the presence of the gallery. This is also true for the shaft when inundated in ground water. 
Accordingly, the season when to carry field surveys is important in gaining similar success in other areas. Therefore, In-gallery seismic shooting is an efficient approach in locating buried shafts and gallery routes, as long as velocity contrast prerequisites are met.

\section{Acknowledgement}

This work is part of the project funded by His Majesty King Abdullah bin Abdulaziz, The Custodian of the Two Holy Mosques, to whom the author deeply grateful and thankful. My extended thanks and gratitude to King Abdulaziz University and the Faculty of Earth Sciences for the support they provided in equipment and transportation, as well as to Dr. M. A. El Difrawy for his lengthy and valuable discussion and his critical review of the manuscript. I am also deeply indebted to the supporting staff of the Geophysics Department of the Faculty of Earth Sciences for their help in conducting the field work.

\section{References}

Alford, R.M., Kelly, K.R. and Boore, D.M. (1974) Accuracy of finite-difference modelling of the acoustic wave equation, Geophysics, 39(6): 834-842.

Alterman, Z. and Karal, F.C. (1968) Propagation of elastic waves in layered media by finitedifference methods, Ball. Seismological Soc. America, 58(1): 367-398.

Black, R.A., Steeples, D.W. and Miller, R.D. (1994) Migration of shallow seismic reflection data, Geophysics, 59 (3): 402-410.

Bore, D.M. (1972) Finite-difference methods for seismic wave propagation in heterogeneous materials, In: Bolt, B.A. (Ed.), Methods in Computational Physics, V II, NY: Academic Press, 1-36.

Brekhovskikh, L. M. (1960) Waves in Layered Media, NY: Academic Press, 561p.

Cerjan, C., Kosloff, D., Kosloff, R. and Reshef, M. (1985) A non-reflecting boundary condition for discrete acoustic and elastic wave equations, Geophysics, 50(4): 705-708.

Chen, K. (1984) Numerical modeling of elastic wave propagation in anisotropic inhomogeneous media: a finite-element approach, SEG Technical Program Expanded Abstracts, 3: 631-632.

Fornberg, B. (1987) The pseudo-spectral method: Comparisons with finite differences for the elastic wave equation, Geophysics, 52(4): 483-501.

Gazdag, J. (1981) Modeling of the acoustic wave equation with transform methods, Geophysics, 46(6): 854-859.

Keiswetter, D., Black, R. and Schmeissner, C. (1996) A program for seismic wavefield modeling using finite-difference techniques, Computers and Geosciences, 22 (3): 267-286.

Kelly, K., Alford, R. and Whitmore, N. (1982) Modeling- the forward method, In: Jain, K., and deFigueiredo, R. (Ed.), Concepts and Techniques in Oil and Gas Exploration, Tulsa, OK: SEG, 92-114.

Kelly, K., Ward, R., Treitel, S. and Alford, R. (1976) Synthetic seismograms, a finite-difference approach, Geophysics, 41(1): 2-27. 
Kosloff, D. and Baysal, E. (1982) Forward modeling by a Fourier method, Geophysics, 47(10): 1402-1412.

Mokhtar, T.A. and El-Difrawy, M.F.I. (2000) In-gallery seismic shooting and surface tomography for investigating ancient galleries in Makkah region, Internat. Confr. Environ. Hazard Mitigation (ICEHM), 2000, University of Cairo, Egypt, Sept. 9-12 (abstract).

Smith, W.D. (1975) The application of finite-element analysis to body wave propagation problems, Geophys. J. Roy. Astro. Soc., 42: 747-768.

Sochacki, J., Kubichek, R., George, J., Fletcher, W.R. and Smithson, S. (1987) Absorbing boundary conditions and surface waves, Geophysics, 52(1): 60-71.

Yilmaz, O. (1987) Seismic Data Processing. SEG Investigations in Geophysics, No. 2, SEG. 


\section{تقويم مصادر الطاقة السيزمية داخل القنوات المائية لاستكثاف الأجز اء المدفونة من عين زبيدة عن طريق نمذجة المجال الصوتي}

\section{طلال علي مختار}

قسم الجبيوفيزياء، كلية علوم الأرض، جامعة الملك عبدالعزيز

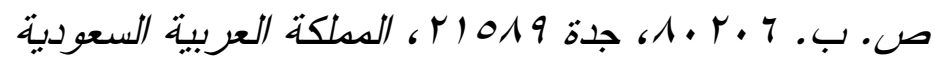
tmokhtar@kau.edu.sa

المستخلص. تم استخدام نهج النمذجة العددية لإيجاد حل غير متجانس وثثائي الأبعاد لمعادلة الموجة الصونية بدقة متتاهية،

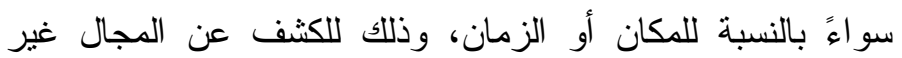
الظاهر الناجم عن مصادر الموجات السيزمية داخل القنوات المائية كطريقة فعالة في تحديد أماكن الخرزات، المدفونة وكذلك مجاري القنوات لعين زبيدة بالقرب من مكة المكرمة في المملكة العربية

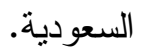

ولقد دلت عمليات النمذجة العددية على أن مجاري القنوات يمكن تحديدها بوضوح من خلال الانعكاسات ذات السعة الكبيرة،

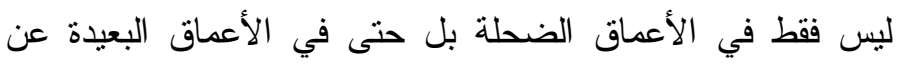

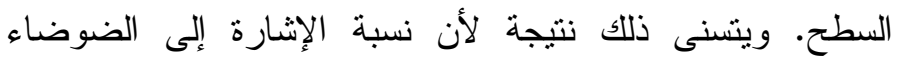

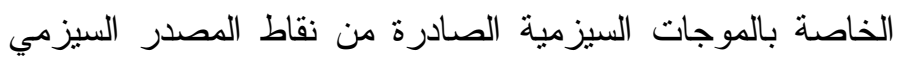
داخل القنوات كانت عالية. وتعتبر هذه الطريقة غير مكلفة لدر اسة

$$
\text { مساحات كبيرة من امتدادات القنو ات بدقة. }
$$


وبالرغم من إمكانية استخدام هذه الطريقة في مناطق مشابهة

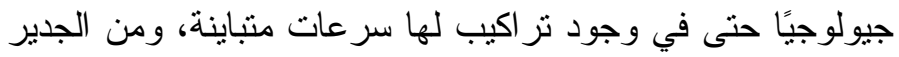

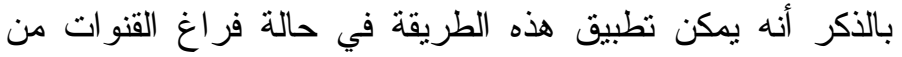

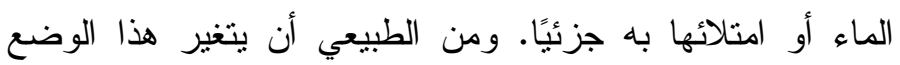

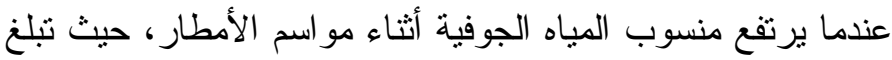
سرعة الموجات السيزمية في الرسوبيات الرخوة سرعتها في الماء

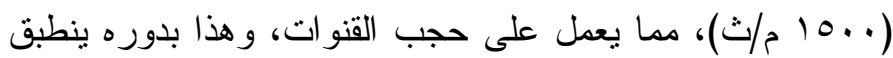

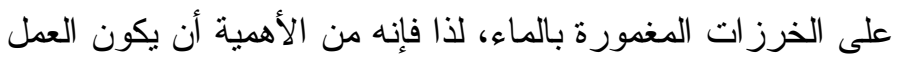
الحقلي في أوقات مناسبة لضمان نجاح الطريقة. 